\title{
Outcome of fertility and pregnancy following hysteroscopic resection of septum using versapoint needle
}

\author{
Vidya V. Bhat ${ }^{1}$, Indranil Dutta ${ }^{2}$, B.S. Bhat ${ }^{3}$, Dilip Kumar Dutta ${ }^{4}$ \\ ${ }^{1}$ Director, Radhakrishna Multispeciality Hospital and IVF Centre, ${ }^{2}$ Assistant Professor, IQ City Medical College, Durgapur, West Bengal, \\ ${ }^{3}$ Senior Consultant, Radhakrishna Multispeciality Hospital and IVF Centre, ${ }^{4}$ Director, Gice Clinic Kalyani, West Bengal, India
}

\section{A B S T R A C T}

\begin{abstract}
Aim: The aim of the present study was to assess the safety and efficacy of hysteroscopic septum resection by Versapoint and future fertility outcome. A total of 105 subfertile patients who underwent hysteroscopic septum resection using the Bipolar Versapoint system were analysed. Methods: Hysteroscopic Metroplasty was performed on 105 patients with uterine septum and history of infertility. The metroplasty procedure was performed on 105 patients using versapoint. The outcome was evaluated based on fertility outcomes. Study Design: Retrospective Experimental study. Results: The pregnancy rates were noted to be around $96.5 \%$ following the procedure and live birth rate were around $82 \%$. Conclusion: Hysteroscopic metroplasty using Bipolar Versapoint had better fertility outcomes and less risks. Future fertility and live birth rates had significantly improved.
\end{abstract}

Key words: Hysteroscopic resection, Versapoint, Septum, Metroplasty

\section{INTRODUCTION}

Mullerian anamolies account for around 5-10\% of infertility problems. Incomplete resorption of mullerian duct during embryogenesis leads to anamolies which alter the reproductive outcome of the patients. Septate uterus can be divided into various classes of which class 5 is the most common ${ }^{1}$ comprising $50 \%$ of mullerian duct anamolies. There are various reasons for reproductive failure and not only limited to septum problem. Septum itself may not be the primary factor all the time. ${ }^{2}$ Sometimes symptoms may not be diagnosed at all. While evaluating the infertile patient we may see an incidental septum present in the fundal region. Earlier days when hysteroscope was not available usually HSG was done to diagnose uterine anamolies, but the treatment of septum was controversial. Post hysteroscopic era, it was found to be an extremely useful instrument which can be used to diagnose as well and be used for therapeutic purpose. Other advantages are shorter hospital stay, reduced risk of adhesions, short operating time and increased rate of vaginal delivery following the procedure, quicker return to normal day to day life activities.

The standard instrument used is the Collen's knife for hysteroscopic resection. But with advent of Versapoint ${ }^{3}$ Bipolar cautery, hysteroscopic septal resection has been easier and safe.

Hence the study was done to evaluate the benefits of hysteroscopic resection using bipolar versapoint needle and to prove its added reproductive outcomes.

\section{MATERIALS AND METHODS}

The reproductive outcome in 105 patients were noted who underwent hysteroscopic septum resection using bipolar versapoint needle in Radhakrishna Multispeciality Hospital and IVF Centre from 2010-2014 and was analysed. Inclusion criteria was all patient with infertility and septum. Exclusion criteria included any other causes of infertility, any other diseases like endometriosis, adhesions, PID, fibroid. 
In our centre the main modality for diagnosing uterine anamolies has been hysteroscopy/office hysteroscopy which should be ideally the gold standard along with ultrasonography. It is the best method for evaluating the infertility case because in this we can easily visualize the cavity by hysteroscope and simultaneously provide treatment on spot if required.

For septal resection - Patient consent was taken before the start of procedure and also was explained about the procedure. In case any operative intervention was required then consent was taken for the same. For septum resection, under general anesthesia, Diagnostic hysteroscope was introduced for analyzing the cavity with normal saline as distension media, and if there was a septum noted then we used versapoint resection electrode. The versapoint system provides three bipolar electrode tip confirgations- twizzle electrode for vaporization and needle like cutting, spring and ball electrode for rapid tissue vaporization. Dilators were used to dilate the cervix enough for the operative hysteroscope to be passed. The operative sheath of versapoint was passed through the port. The septum was divided from one edge to other till both the ostia were visible in single operative field. Bleeding dots noted at the fundus suggested our depth. Resection was stopped at 5-6 $\mathrm{mm}$ distance. There is almost no complication seen in the procedure like perforations, thermal injury etc. Post procedure the patients were started with hormones for endometrium rebuilding for 3-4 cycles. Usually estrogen valerate was used post procedure. Estrogen (Progynova $2 \mathrm{mg}$ ) twice daily for 25 days followed by Medroxy progesterone acetate (Meprate $10 \mathrm{mg}$ ) twice daily for 5 days.Estrogen for enhancing endometrial growth and terminal phase progesterone for shedding.

After the treatment patients were advised Natural conception/IUI/IVF. In case of missed period, $\beta$ hCG was done followed by ultrasonography. Patients were followed upto delivery in our centre. Though Laparoscopic guided hysteroscopic resection is commonly done, but because of the surgeon's experience of cases, no laparoscopy was required in any of our cases.

Concomittant laparoscopy during hysteroscopic septal resection serves two purposes.

a. Differentiation between bicornuate and septal uterus, which can diagnosed by HSG and 3D 4D Ultrasound.

b. Monitors hysteroscopic surgery. Complication can be prevented and infertility workups of the patient can be simultaneously. The learning curve is more, so the surgeon should have at least done 20-25 septal resection to confidently do this procedure without laparoscopy.
The average saline used was 3.5 to 4 litres. Since we closely monitor the intake output chart, the fluid retained was about 200 to $250 \mathrm{ml}$ saline in all cases.

Average operating times 10-18 minute.

\section{Stastistical analysis}

The analysis was performed using SPSS Software (US). Continuous variables were presented as mean and SD and were analyzed by independent t-test. Categorical data are represented by frequency with percentage and were analyzed by $\mathrm{Chi}$ square test. $\mathrm{P}<0.05$ was considered significant.

\section{RESULTS}

Resection of the septum was undertaken with ease. Around 65 had complete septum and 40 had partial septum of the total 105 cases. Using Versapoint Bipolar system has been found to be a very easy to use method of resection with minimal to no complications at all. Table 1 has been found to show the general demographic features of the patients and the mean followup. Total number of patients were found to be 62 in primary infertility cases of which mean age was around 27 and in cases of secondary infertility the mean age was found to be 29 . Followup was good considering it to be around atleast 10 month for both sets. Table 2 illustrates the reproductive outcome following use of the Versapoint needle for septum resection. It was seen that out of 62 patients around 54 had conceived ( $87 \%$ ) in primary infertility cases with $72.5 \%$ having natural cycles, $11.2 \%$ having ART techniques used and $3.2 \%$ of miscarriages. In secondary infertility cases of total 43 cases, 42 cases i e., $97.6 \%$ of the cases had conceived of which $88.4 \%$ had natural pregnancies, $4.6 \%$ required ART techniques and $4.6 \%$ had miscarriages.

\begin{tabular}{lcc} 
Table 1: Characteristics of the patients \\
\hline Parameters & $\begin{array}{c}\text { Primary infertility } \\
\text { (mean } \pm \text { SD) }\end{array}$ & $\begin{array}{c}\text { Secondary infertility } \\
\text { (mean } \pm \text { SD) }\end{array}$ \\
\hline No of patients & 62 & 43 \\
Age (years) of patients & $27 \pm 3.02$ & $29 \pm 4.12$ \\
Time period of follow & $11 \pm 6.18$ & $8 \pm 1.12$ \\
up (months) & & \\
\hline
\end{tabular}

\begin{tabular}{lcc}
\multicolumn{3}{l}{ Table 2: Reproductive outcome } \\
\hline $\begin{array}{l}\text { Pregnancies } \\
\text { and methods }\end{array}$ & $\begin{array}{c}\text { Primary } \\
\text { infertility }\end{array}$ & $\begin{array}{c}\text { Secondary } \\
\text { infertility }\end{array}$ \\
\hline Pregnancies $(\mathrm{n})$ & $54(87 \%)$ & $42(97.6 \%)$ \\
Natural $(\mathrm{n})$ & $45(72.5 \%)$ & $38(88.37 \%)$ \\
ART $(\mathrm{n})$ & $7(11.2 \%)$ & $2(4.6 \%)$ \\
Miscarriages $(\mathrm{n})$ & $2(3.2 \%)$ & $2(4.6 \%)$ \\
\hline
\end{tabular}




\section{DISCUSSION}

This study shows that hysteroscopic metroplasty improves the outcome or the chances of future pregnancies particularly by use of versapoint needle. However the finding in this study correlates with various other studies. ${ }^{4}$ The rate of miscarriages also reduces considerably. Many esteemed authors also believe that metroplasty should only be done after an event of RPL but it is a debatable question as because many times when during a routine Diagnostic hysteroscopic method in our setup we happen to find an incidental septum for which immediate action can be taken. It is also supported by various studies supporting prophylactic metroplasty. ${ }^{4,5}$ But hysteroscopic approach under direct vision definitely helps in restoring fertility status.

Collen's knife is a monopolar cautery, distension media used usually is glycine compared to versa point which is bipolar cautery, distension media used is saline. For collen's cervical dilatation has to be around $11 \mathrm{~mm}$ compared to $9 \mathrm{~mm}$ in versapoint. Bipolar itself is safer compared to monopolar. Lateral spread of current with bipolar is less and endometrial damage is less which aids in fertility later on. Complications of Collen's knife includes- increased chances of cervical injury, perforation, other complications of TURP Syndrome.

No rates of complications/reduced fertility has been noted in our case series. There has been various debate regarding the use of estrogen therapy after the septum resection but studies have again proved the benefits of those. ${ }^{6-9}$

Routine use of antibiotic therapy after the procedure has been followed in our setup as in India, hygiene of the patient is debatable. Presently hysteroscopic metroplasty is considered as a gold standard for septum resection. Use of versa point needle even supports the procedural outcome as ${ }^{6}$ it has a very good outcome. But there are certain risks of hysteroscopic approach which has to be noted. Over judicious metroplasty may weaken the fundal area and adequate spacing if not given between procedures and conceiving may result in rupture. Though incidences are extremely rare. ${ }^{10-12}$ Hence surgeon expertise in understanding the mechanism of hysteroscopy is also of utmost importance.
Office hysteroscopy was done at the end of three months for our patients which showed normal endometrium at the fundus.

Hence our study proves that hysteroscopic metroplasty using bipolar versapoint needle is definitely a useful modality for fertility outcone in septum cases.

\section{CONCLUSION}

This study proves the role of versapoint needle in cases of hysteroscopic metroplasty and that metroplasty itself resolves the fertility status of the patients with septum with history of primary/secondary infertility.

\section{REFERENCES}

1. American Fertility society. Classification of mullerian anomalies. FertilSteril 1988; 49: 944-955.

2. Heinonen PK. Complete septate uterus with longitudinal vaginal septum. FertilSteril 2006; 85: 700-705.

3. Zicopoulos KA, Kolibianakis EM, Tournaye H, de Munck L, Devroey $\mathrm{P}$ and Camus M. Hysteroscopic septum resection using the Versapoint system in subfertile women. Reprod Biomed Online 2003; 7(3):365-367.

4. Homer HA, Tin-Chiu L and Cook ID. The septate uterus: A review of management and reproductive outcome. FertilSteril 2000; 73:1-24.

5. Chen PF, Chou PY, Shay $P$ and $\mathrm{Wu} \mathrm{MH.} \mathrm{Hysteroscopic}$ intervention in septate uterus and intrauterine synechiae: Gynecology and Minimally Invasive Therapy 2013; 2(1):34-37.

6. Israel $\mathrm{R}$ and March CM. Hysteroscopic incision of the septate uterus. Am J Obstet Gynecol 1984; 149:66-68.

7. Valle RF and Sciarra JJ. Hysteroscopic treatment of the septate uterus. Obstet Gynecol 1986; 67: 253-257.

8. Perino A, Mencaglia L, Hamou J and Cittadini E. Hysteroscopy for metroplasty of uterine septa: Report of 24 cases. FertilSteril 1987; 48: 321-323.

9. Tonguc EA, Var T, Yilmaz N and Batioglu S. Intrauterine device or estrogen treatment after hysteroscopic uterine septum resection. Int J Gynaecol Obstet 2010; 109(3):226-229.

10. Angell $N$, Domingo $T$ and Siddiqi $N$. Uterine rupture at term after uncomplicated hysteroscopic metroplasty. Obstet Gynecol 2002; 100: 1098-1099.

11. Conturso R, Redaelli L, Pasini A and Tenore A. Spontaneous uterine rupture with amniotic sac protrusion at 28 weeks subsequent to previous hysteroscopic metroplasty. Eur J Obstet Gynecol Reprod Biol 2003; 107: 98-100.

12. Howe RS. Third-trimester uterine rupture following hysteroscopic uterine perforation. Obstet Gynecol 1993; 81: 827-829. 